\title{
ANALISIS PELUANG DAN TANTANGAN PERGURUAN TINGGGI BERDASARKAN BAURAN PEMASARAN (STUDI KASUS UPBJJ-UT TERNATE)
}

\section{Analysis Of Education Opportunities And Challenges Based On Marketing Mix (Case Study In UPBJJ-UT Ternate)}

\author{
Anfas \\ e-mail: anfas_st_mm@ecampus.ut.ac.id \\ Jurusan Manajemen, Fakultas Ekonomi, Universitas Terbuka \\ Jl. Cabe Raya, Pondok Cabe, Pamulang, Tangeran Selatan
}

\section{Zainuddin \\ e-mail: zainudin@unkhair.ac.id}

Program Studi Akuntansi, Fakultas Ekonomi dan Bisnis, Universitas Khairun

Jl. Jusup Abdurrahman, Kel.Gambesi, Kota Ternate, Maluku Utara

\begin{abstract}
ABSTRAK
Tujuan penelitian ini adalah untuk mengukur peluang dan tantangan UPBJJ-UT Ternate melalui ekspektasi siswa SLTA terhadap komponen bauran pemasaran jasa, terdiri dari produk, harga, tempat, promosi, sumber daya manusia, aktivitas operasional dan sarana prasarana. Penelitian ini adalah penelitian deskriptif kualitatif. Data penelitian diperoleh dari hasil penyebaran kuisioner dan wawancara kepada siswa SLTA kelas XII di Maluku Utara yang menjadi sampel, yakni 801 Siswa. Data dianalisis menggunakan model Milles dan Michael Huberman dengan tahapan pengumpulan data, reduksi data, penyajian data, dan penarikan kesimpulan. Hasil penelitian menunjukkan: 1) berdasarkan bauran pemasaran, siswa SLTA di Maluku Utara lebih mempertimbangkan masuk ke Perguruan Tinggi yang mempunyai program studi/jurusan yang sesuai minatnya, SPP-nya terjangkau, lokasinya dekat pusat kota, memiliki dosen yang kapabel, proses pendaftarannya mudah diakses, dan meiliki sarana prasarana ruang belajar yang nyaman. 2) UPBJJ-UT Ternate mempunya peluang dalam melakukan sosprom ke siswa SLTA karena sebagian besar dari mereka belum memutuskan memilih masuk ke perguruan manapun. Apalagi di UT banyak tersedia beasiswa seperti Bidimisi dan CSR UT tentu akan menarik minat mereka untuk kuliah di UT. 3) Dari aspek tantangan, saat ini sudah banyak Perguruan Tinggi di Maluku Utara, sehingga UPBJJ-UT Ternate harus mampu memberikan sosialisasi tentang keunggulan UT dari perguruan tinggi lainnya yang ada di Maluku Utara, seperti: proses pendaftarannya terbuka untuk umum dan segala Usia, biayanya terjangkau dan dapat kuliah di mana saja sehingga mudah diakses.
\end{abstract}

Kata Kunci: Bauran Pemasaran, Ekspektasi, Analisis SWOT, Peluang

\section{ABSTRACT}

The purpose of this study was to measure the opportunities and challenges of UPBJJ-UT Ternate through high school students' expectations of the marketing mix of higher education services, namely product, price, place, promotion, human resources, operational activities and 
infrastructure. This research is a qualitative descriptive study. Sources of information were obtained from the results of distributing questionnaires and interviews to class XII SMA students throughout North Maluku who became the sample, namely 801 students. Data analysis used the model of Milles and Michael Huberman with the stages of data collection, data reduction, data presentation, and drawing conclusions. The results showed: 1) based on the marketing mix, high school students in North Maluku were more likely to consider entering a university that had a study program/department that matched their interests, affordable tuition fees, located near the city center, had lecturer qualifications, process easy access registration., and has a comfortable study room infrastructure. 2) UPBJJ-UT Ternate had the opportunity to hold a social media program for high school students because most of them have not yet decided to enter any university. Moreover, there are many scholarships available at UT, such as Bidimisi and UT CSR, which will certainly attract them to study at UT. 3) From the aspect of challenges, currently there are many universities in North Maluku, so UPBJJ-UT Ternate must be able to provide socialization about the advantages of UT from other universities in North Maluku, such as: the registration process is open to the public and all ages, the cost is affordable and can study anywhere so that it is easily accessible.

\section{Keywords: Marketing Mix, Expectations, SWOT Analysis, Opportunities}

\section{PENDAHULUAN}

Tujuan Universitas Terbuka (UT) didirikan oleh pemerintah tahun 1984 adalah untuk meningkatkan angka partisipasi kasar Perguruan Tinggi di tanah air. Hal ini tercermin dari isi pidato Presiden Soeharto saat meresmikan UT di Istana Negara yang menyatakan bahwa melalui pengembangan sistem pendidikan terbuka dan jarak jauh yang diselenggarakan UT maka diharapkan dapat menampung para lulusan SLTA yang tidak dapat melanjutkan pendidikan di Perguruan Tinggi tatap muka karena keterbatasan daya tampung. Seiring perjalan waktu, guna dapat menjalankan misinya, maka UT membetuk kantor Unit Program Belajar Jarak Jauh Universitas Terbuka (UPBJJ-UT) di daerah. Hingga kini ada sebanyak 39 Kantor UPBJJ-UT yang tersebar di 34 Provinsi di Indonesia dan ditambah 1 kantor unit layanan mahasiswa yang melayani mahasiswa yang tersebar di 32 negara di luar negeri.

Kantor UPBJJ-UT inilah yang selanjutnya berupaya melakukan sosialisasi dan promosi kepada masyarakat guna dapat mengakses layanan pendidikan tinggi yang diselenggarakan oleh UT. Namun demikian, banyak masyarakat yang belum menjadikan UT sebagai pilihan strategis untuk kuliah. Mereka masih menganggap UT hanyalah suatu perguruan tinggi yang dikhususkan bagi pekerja. Ada pula yang menganggap remeh standar mutu UT. Bahkan ada yang belum tau jika UT adalah Perguruan Tinggi Negeri milik pemerintah. Padahal dengan sistem pendidikan terbuka dan jarak jauh yang diselenggarakan oleh UT, memungkinkan untuk dapat menampung 
mahasiswa sebanyak-banyaknya, karena tidak dibatasi kuota kelas sebagaimana yang berlaku di Perguruan Tinggi tatap muka. Dengan keunggulan ini maka akan mampu meningkatkan Angka Partisipasi Kasar (APK) Perguruan Tinggi.

Sebagaimana data Kemenristekdikti menunjukkan bahwa walaupun tiap tahun mengalami peningkatan, namun APK Pendidikan Tinggi Indonesia tetap masih kalah dibandingkan negara-negara lain di kawasan asia. Di tahun 2012 sebesar 28\%, kemudian tahun 2013 naik 33\%. Tahun 2015 meningkat 33,66\%, namun tahun 2018 kembali menjadi 30,19\%. Rendahnya APK Pendidikan Tinggi di Indonesia tentunya menjadi pekerjaan rumah bersama bagi pemerintah, terutama di wilayah timur Indonesia, termasuk di Provinsi Maluku Utara. Data BPS Maluku Utara 2010, menunjukkan bahwa dari 109.120 masyarakat Maluku Utara umur 19 24 tahun, hanya 5.855 (5,37\%) yang melanjutkan studinya ke Perguruan Tinggi. Selanjutnya data Kemedikbud tahun 2013, menunjukkan dari 109.450 penduduk Maluku Utara yang berumur 1923 tahun yang dapat lanjutkan ke Pendidikan Tinggi hanya 29.368 (30,45\%). Artinya masih ada $7.122(69,55 \%)$ yang belum berkesempatan kuliah.

Kecilnya APK Pendidikan Tinggi di atas, maka tentunya dengan keberadaan UT melalui UPBJJ-UT Ternate di Maluku Utara menjadi sebuah solusi bagi lulusan SLTA untuk melanjutkan pendidikannya di Perguruan Tinggi. Peluang tersebut tentunya sangat besar, sebab dari data Registrasi 2018.2 UPBJJ-UT Ternate menunjukkan bahwa dari 1.306 mahasiswa Non Pendas yang melakukan registrasi, baru 44 (3,37\%) yang berusia dibawah 21 tahun.

Dalam penelitian ini, peneliti mencoba menggali lebih dalam guna mengetahui peluang dan tantangan UPBJJ-UT Ternate berdasarkan ekspektasi siswa SLTA di Maluku Utara yang akan menjadi calon mahasiswa. Instrumen penelitian yang dipakai adalah strategi bauran pemasaran pendidikan tinggi: Produk (product), Harga (price), Tempat (place), Promosi (promotion), Sumber daya Manusia (people), aktivitas operasional (process) dan sarana prasarana (physical evidence) yang menunjang jalannya proses pembelajaran di Perguruan Tinggi.

\section{METODE PENELITIAN}

Jenis penelitian ini adalah penelitian gabungan antara kualtitatif dan kualitatif (mixed methods), dengan tujuan utama untuk membuat gambaran/deskriptif tentang suatu keadaan secara obyektif agar dapat digunakan untuk memecahkan masalah yang sedang dihadapi. 
Populasi penelitian adalah siswa kelas XII di SLTA yang ada di Provinsi Maluku Utara. Sedangkan sampel dalam penelitian ini dipilih secara acak yakni 801 siswa. Untuk mendapatkan informasi yang mendalam tentang topik penelitian, maka data penelitian tidak hanya melaui kuisioner namun juga dilakukan wawancara mendalam (Indepth interview) pada beberapa informan yang diambil dari sampel. Para informan ditentukan dengan cara purpousive sampling, dengan kriteria: sudah punya perencanaan kuliah dan bersedia diwawancara. Analisis data menggunakan metode Miles dan Huberman (2007: 69), dimana analisis data dilakukan secara interaktif dan berlangsung terus menerus sampai tuntas. Aktivitas analisis data meliputi reduksi data, penyajian data, penarikan kesimpulan.

\section{HASIL DAN PEMBAHASAN}

Berikut disajikan tabel deskripsi data responden Berdasarkan pengklasifikasian gender responden penelitian;

Tabel 1. Data Jenis Kelamin Responden

\begin{tabular}{ccc}
\hline Keterangan & Jumlah Responden & Persentase \\
\hline Laki- Laki & 304 & $37,95 \%$ \\
Perempuan & 497 & $62,05 \%$ \\
\hline Jumlah & 801 & $100 \%$ \\
\hline
\end{tabular}

Sumber : Data primer diolah, peneliti 2018.

Berdasarkan tabel di atas, responden laki-laki berjumlah 304 (36,23\%) dan perempuan 497 (63,77\%). Dari 801 sampel di atas, yang kuisionernya diisi lengkap sebanyak 742, sehingga selanjutnya data tersebutlah yang digunakan.

\section{Ekspektasi responden terhadap variabel Product}

Tabel 2. Ekspektasi Responden Terhadap Variabel Produk

\begin{tabular}{llcc}
\hline No & \multicolumn{1}{c}{ Indikator } & Jumlah & Persentase \\
\hline 1 & Kurikulum & 72 & $17,14 \%$ \\
2 & Jurusan/Program Studi & 103 & $24,52 \%$ \\
3 & Magang & 76 & $18,10 \%$ \\
4 & KKN & 83 & $19,76 \%$ \\
5 & Akreditas & 86 & $20,48 \%$ \\
\hline \multicolumn{2}{c}{ Jumlah } & 742 & $100 \%$
\end{tabular}

Sumber : data primer diolah, peneliti 2018

Mayoritas responden menyatakan akan melanjutkan pendidikannya jika jurusan atau program studi sesuai dengan minat mereka. Dari wawancara responden dengan Nur Fitri Indah 
Sari, salah seorang siswi SMK Bhakti Persada jurusan Keperawatan berpendapat bahwa: “...sangat penting memilih jurusan sesuai dengan cita-cita, bakat dan minat. Karena dengan memilih jurusan yang sesuai dengan minat dan bakat kita, kita bisa melihat jurusan tersebut membawa kita ke profesi dan cita-cita kita"

Hurriyati (2009) menyatakan bahwa dalam jasa pendidikan tinggi, produk/jasa yang ditawarkan kepada mahasiswa adalah reputasi/mutu pendidikan yang baik, prospek yang cerah bagi mahasiswa setelah lulus dari perguruan tinggi, dan pilihan konsentrasi yang bervariasi sesuai dengan bakat dan minat. Reputasi dan prospek perguruan tinggi seperti menghasilkan lulusan yang memiliki kompetensi baik serta bisa diterima di dunia kerja dengan mudah.

Sejalan dengan hasil penelitian Muhyidin (2015) membuktikan bahwa variabel product berpengaruh secara signifikan. Hal ini menunjukkan bahwa program studi dengan kosentrasi dan akreditasi yang ditawarkan akan berpengaruh langsung terhadap keputusan mahasiswa memilih perguruan tinggi. Hasil yang sama ditunjukkan oleh penelitian Samat, dkk (2017) yang menyatakan bahwa variabel product (produk) berpangaruh signifikan dan positif terhadap keputusan mahasiswa memilih perguruan tinggi swasta di kota Palembang. Hasil ini mencerminkan semakin tinggi intensitas produk yang terdapat pada PTS tersebut yang meliputi kurikulum dan silabus, status jurusan/program studi, laboratorium, perpustakaan, teknologi dan media pembelajaran, staf pengajar dan desain fasilitas. Kuliah di PTS elit tersebut akan mengangkat derajat dan pengakuan dari masyaralat, sehingga tentu saja akan diminati calon mahasiswa.

\section{Ekspektasi responden terhadap variabel Price}

Tabel 3. Ekspektasi Responden Terhadap Variabel Harga

\begin{tabular}{llcc}
\hline No & \multicolumn{1}{c}{ Indikator } & Jumlah & Persentase \\
\hline 1 & Biaya SPP Terjangkau & 180 & $42,86 \%$ \\
2 & Biaya Ujian yang murah & 77 & $18,33 \%$ \\
3 & Bebas Biaya Pendaftaran & 60 & $14,29 \%$ \\
4 & Bebas Biaya Sumbangan & 21 & $5,00 \%$ \\
5 & Biaya Buku Terjangkau & 82 & $19,52 \%$ \\
\hline \multicolumn{2}{r}{ Jumlah } & 742 & $100 \%$ \\
\hline
\end{tabular}

Sumber : data primer diolah, peneliti 2018

Dari tabel di atas, terlihat bahwa biaya SPP yang terjangkau menjadi ekspektasi mayoritas siswa. Hal ini sejalan dengan hasil wawancara dengan Wesi Pola, salah seorang siswi 
SMA Dian Halmahera jurusan IPA berpendapat bahwa: “...saya memilih perguruan tinggi menyesuaikan dengan kondisi ekonomi orang tua juga. Saya berusaha untuk masuk ke perguruan tinggi negeri dan memperoleh beasiswa.”

Berdasarkan tanggapan salah seorang responden di atas, tampak jelas bahwa harga menjadi salah satu pertimbangan siswa dalam memilih perguruan tinggi. Harga menurut Kotler \& Armstrong (2008) adalah sejumlah nilai atau uang yang dibebankan pada suatu produk/jasa yang ditanggung konsumen. Pada perguruan tinggi, biaya kuliah yang dibayar mahasiswa per semester merupakan harga yang harus mereka bayarkan untuk mendapatkan jasa layanan pendidikan.

Besarnya biaya kuliah untuk jasa pendidikan tinggi sangat dipengaruhi oleh kualitas pendidikan atau kurikulumnya. Jika kualitas pendidikannya telah teruji dan telah diakui oleh masyarakat karena lulusannya banyak terserap di lapangan kerja, maka calon mahasiswa bersedia untuk membayar lebih mahal, selama masih terjangkau oleh mereka (Alma, 2009). Dalam konteks ini, harga merupakan keseluruhan biaya yang dikeluarkan oleh mahasiswa selama kuliah di perguruan tinggi. Untuk itu, dalam penetapan harga, perlu dipertimbangkan antara lain adalah besaran SPP, biaya pembangunan dan biaya laboratorium, pemberian beasiswa dan prosedur pembayaran (Hurriyati, 2009).

\section{Ekspektasi responden terhadap variabel Place}

Tabel 4. Ekspektasi Responden Terhadap Variabel Tempat

\begin{tabular}{llcc}
\hline No & \multicolumn{1}{c}{ Indikator } & Jumlah & Persentase \\
\hline 1 & Berada di tengah kota & 105 & $25,00 \%$ \\
2 & Dekat dengan Pusat Belanja & 72 & $17,14 \%$ \\
3 & Dekat dengan Kampus Lainnya & 55 & $13,10 \%$ \\
4 & Dekat dengan area Perkantoran & 97 & $23,10 \%$ \\
5 & Dekat dengan Tempat Tinggal & 91 & $21,67 \%$ \\
\hline & Jumlah & 742 & $100 \%$ \\
\hline
\end{tabular}

Sumber : data primer diolah, peneliti 2018

Dari tabel 4, menunukkan bahwa semua indikator pada variabel tempat/letak kampus diperhitungkan siswa dalam memilih perguruan tinggi. Dari 742 responden yang memilih akan kuliah, mayoritas siswa akan memilih perguruan tinggi yang terletak di pusat kota. Hal ini berarti bahwa keberadaan kampus di pusat kota, dekat tempat tinggal (rumah/tempat Kos), lingkungan belajar yang kondusif, dan terjangkau transportasi umum, memberikan pengaruh langsung 
terhadap keputusan siswa memilih perguruan tinggi. Hal ini sejalan dengan hasil penelitian yang dilakukan oleh Muhyidin (2015) yang menyatakan bahwa place berpengaruh terhadap keputusan mahasiswa memilih perguruan tinggi. Perguruan tinggi perlu mempertimbangkan letak kampus berada (dekat pusat kota atau perumahan) dan kemudahan transportasi agar mudah diakses. Menurut Alma (2009), lokasi strategis dan mudah diakses oleh kendaraan umum, akan menjadi daya tarik bagi calon mahasiswa. Selain itu, juga mudah dijangkau secara virtual melalui internet sehingga perlu ketersediaan website perguruan tinggi.

\section{Ekspektasi responden terhadap variabel Promotion}

Tabel 5. Ekspektasi Responden Terhadap Variabel Promosi

\begin{tabular}{llcc}
\hline No & \multicolumn{1}{c}{ Indikator } & Jumlah & Persentase \\
\hline 1 & Promosi di Surat Kabar/Media Cetak & 53 & $12,62 \%$ \\
2 & Promosi di Radio/Media Elektronik & 40 & $9,52 \%$ \\
3 & Promosi di Papan Reklame & 70 & $16,67 \%$ \\
4 & Sosprom secera Tatap Muka di Sekolah & 169 & $40,24 \%$ \\
5 & Promosi di Media Sosial & 88 & $20,95 \%$ \\
\hline & Jumlah & 742 & $100 \%$ \\
\hline
\end{tabular}

Sumber : data primer diolah, peneliti 2018

Dalam penelian Erwin dan Permata (2020), menunjukkan bahwa promosi dan periklanan berpengaruh terhadap keputusan konsumen. Sejalan dengan penelitian Samat dkk (2017) dan Muhyidin (2015) menemukan bahwa promosi berpengaruh positif dan signifikan terhadap keputusan mahasiswa dalam memilih perguruan tinggi. Alma (2009) mengemukakan promosi adalah komunikasi yang menginformasikan kepada pelanggan potensial mengenai kerberadaan sebuah produk atau jasa lalu membujuk mereka untuk memilih produk/jasa yang memiliki kapabilitas memuaskan tersebut.

Dalam penelitian ini, responden yang menyatakan akan melanjutkan pendidikan tingginya, mayoritas lebih senang ketika adanya kunjung sosialisasi dan promosi (sosprom) ke sekolah mereka. Promosi melalui sosialisasi langsung ke sekolah merupakan jenis promosi yang paling diharapkan oleh siswa karena selain informasi yang disampaikan dapat langsung diterima oleh siswa, hal-hal yang masih kurang jelas dapat ditanyakan langsung kepada pihak universitas yang diwakili oleh promotor yang hadir ke sekolah. Hal ini sebagaimana diungkapkan oleh mayoritas siswa di kota Ternate, Tidore dan kabupaten Halmahera Barat. M. Fauzan Abbas, salah seorang siswa dari SMA N 4 Kota Ternate, menuturkan bahwa: “... selama ini, saya tau 
UT hanya dari nama dan alamatnya saja yaitu kampus di sekitar mangga dua. Namun saya belum mengetahui secara rinci mengenai program studi dan kurikulumnya. Saya mengharapkan pihak UT hadir ke sekolah dan memberikan informasi dan sosialisasi kepada kami, supaya kami dapat memperoleh gambaran umum tentang universitas terbuka”. Hal senada disampaikan oleh Fifin Riyani, siswa SMA N 6 Kota Tidore Kepulauan: “... saya dan teman-teman belum mengetahui apa itu UT. Menurut saya, sosialisasi yang efektif adalah sosialisasi yang langsung tatap muka di kelas agar supaya semua pertanyaan yang ada di kepala siswa dapat langsung ditanyakan.”

Berdasarkan argumentasi di atas, kiranya dapat mewakili bahwa promosi merupakan salah satu bauran pemasaran pendidikan tinggi yang penting.

\section{Ekspektasi responden terhadap variabel People}

Tabel 6. Ekspektasi Responden Terhadap Variabel Sumber Daya Manusia

\begin{tabular}{llcc}
\hline No & \multicolumn{1}{c}{ Indikator } & Jumlah & Persentase \\
\hline 1 & Kualifikasi Dosen/Tutor & 122 & $29,05 \%$ \\
2 & Profesionalitas Manajemen & 109 & $25,95 \%$ \\
3 & Staf Tata Usaha yang aspiratif & 81 & $19,29 \%$ \\
4 & Staf Biro Akademik yang ramah & 59 & $14,05 \%$ \\
5 & Petugas Kebersihan yang rajin & 49 & $11,67 \%$ \\
\hline & Jumlah & 742 & $100 \%$ \\
\hline
\end{tabular}

Sumber : data primer diolah, peneliti 2018

Dari tabel di atas, menunjukkan bahwa semua indikator variabel sumber daya manusia merupakan komponen yang menentukan bagi siswa dalam memilih perguruan tinggi. Terutama dari aspek kualifikasi pendidikan dosen/tutor. Lupiyoadi \& Hamdani (2009) menyatakan bahwa dalam pemasaran jasa, SDM yang tersedia sangat mempengaruhi kualitas jasa yang diberikan. Semua sikap dan perilaku karyawan, bahkan cara berpakaian dan penampilan karyawan berpengaruh terhadap persepsi konsumen atau keberhasilan penyampaian jasa (service encounter). Sebab merekalah yang akan terlibat langsung dalam menjalankan segala aktivitas dalam pelayanan kepada pelanggan (Hurriyati, 2005). Dalam kaitannya dengan perguruan tinggi, sumber daya manusia meliputi tenaga dosen, tenaga administrator dan pegawai lainnya. Mereka perlu memiliki kompetensi yang tinggi (terutama dosen) sebab senantiasa berinteraksi langsung dengan para mahasiswa (Hurriyati, 2009). 
Journal of Economic, Public, and Accounting (JEPA)

ISSN Online 2623-2472

Vol.4 No. 1 Oktober 2021, hlmn. 1-12

ISSN Cetak 2715-8977

\section{Ekspektasi responden terhadap variabel Process}

Tabel 7. Ekspektasi Responden Terhadap Variabel Aktivitas Operasional

\begin{tabular}{llcc}
\hline No & \multicolumn{1}{c}{ Indikator } & Jumlah & Persentase \\
\hline 1 & Penerimaan mahasiswa baru yang selektif & 105 & $25,00 \%$ \\
2 & Pendaftaran mahasiswa baru yang simpel & 120 & $28,57 \%$ \\
3 & Prosedur test yang objektif & 91 & $21,67 \%$ \\
4 & Kuliah tatap muka di kelas & 75 & $17,86 \%$ \\
5 & Kuliah fleksibel melalui online & 29 & $6,90 \%$ \\
\hline & Jumlah & 742 & $100 \%$
\end{tabular}

Sumber : data primer diolah, peneliti 2018

Dari tabel di atas, 28,57\% siswa akan memilih kampus dengan proses pendaftarannya yang simple. Zethaml \& Bitner (2000: 20) mendefinisikan proses sebagai prosedur, mekanisme dan rangkaian kegiatan untuk menyampaikan jasa dari produsen ke konsumen. Pada lembaga pendidikan, proses adalah serangkaian kegiatan yang dialami mahasiswa selama pendidikan, mulai dari proses pendaftaran, registrasi matakuliah, proses belajar mengajar, ujian, bimbingan tesis, wisuda dan aktifitas lainnya yang menunjang proses belajar. Hasil penelitian Muhyidin (2015) menemukan bahwa proses berpengaruh signifikan terhadap keputusan mahasiswa memilih perguruan tinggi. Hasil sebaliknya ditunjukkan oleh penelitian Samat, dkk (2017).

\section{Ekspektasi responden terhadap variabel Physical Evidance}

Tabel 8. Ekspektasi Responden Terhadap Variabel Sarana dan Prasarana

\begin{tabular}{|c|c|c|c|}
\hline No & Indikator & Jumlah & Persentase \\
\hline 1 & Gedung kuliah yang bagus & 97 & $23,10 \%$ \\
\hline 2 & Ruang kelas yang nyaman & 108 & $25,71 \%$ \\
\hline 3 & Tersedianya ruang ibadah & 102 & $24,29 \%$ \\
\hline 4 & Akses Internet yang lancar & 82 & $19,52 \%$ \\
\hline 5 & Fasilitas Laboratorium dan Kantin & 31 & $7,38 \%$ \\
\hline & Jumlah & 742 & $100 \%$ \\
\hline
\end{tabular}

Sumber : data primer diolah, peneliti 2018

Dari tabel di atas, terlihat bahwa semua indikator pada variabel sarana prasarana (Sarpras) dinilai oleh siswa dalam memilih perguruan tinggi. Mayoritas siswa memilih perguruan 
tinggi yang memiliki ruang kelas yang nyaman. Hasil wawancara dengan Ummu Khumairah Maat, salah satu siswi SMA N 3 Halbar, memberikan pandangan terkait sarana dan prasarana yang dibutuhkan siswa dari perguruan tinggi: “... menurut saya, kampus yang bagus adalah yang memiliki fasilitas memadai untuk belajar seperti ruang belajar yang nyaman, memiliki laboratorium, kantin yang bersih, memiliki fasilitas internet dan dekat dengan tempat ibadah".

Pernyataan diatas mengindikasikan bahwa kondisi gedung yang megah dan luas, ruang kuliah dan kelengkapan media belajar mengajar yang memadai berpengaruh secara signifikan terhadap keputusan mahasiswa memilih perguruan tinggi. Hasil penelitian Muhyidin (2015) menemukan bahwa physical evidence memiliki pengaruh positif dan signifikan terhadap keputusan mahasiswa dalam memilih perguruan tinggi.

\section{Analisis SWOT}

Berdasarkan ekspektasi siswa dalam memilih perguruan tinggi berdasarkan bauran pemasaran jasa, maka dilakukan analisa kekuatan dan kelemahan terhadap kondisi internal perguruan tinggi, serta analisa terhadap peluang dan ancaman yang dihadapi terhadap kondisi eksternal. Berikut disajikan analisis SWOT UT-UPBJJ Ternate:

Tabel 9. Analisis SWOT UT-UPBJJ Ternate

\begin{tabular}{c|l|c|l}
\hline \multicolumn{1}{c|}{ STRENGTH } & \multicolumn{2}{c}{ WEAKNESS } \\
\hline 1 & Terbuka untuk umum dan segala Usia & 1 & Sumber daya manusia terbatas \\
\hline 2 & Biaya Pendidikan terjangkau & 2 & Brand UT di masyarakat masih lemah \\
\hline 3 & Proses Pendaftaran yang Mudah & 3 & $\begin{array}{l}\text { Pokjar di daerah belum beroperasi } \\
\text { maksimal }\end{array}$ \\
\hline 4 & Lokasi Strategis di pusat kota & 4 & $\begin{array}{l}\text { Sosialisasi melalui tatap muka } \\
\text { langsung masih terbatas }\end{array}$ \\
\hline 5 & $\begin{array}{l}\text { Sarana dan Prasarana perkuliahan } \\
\text { berkualitas }\end{array}$ & & \multicolumn{2}{|c}{ THREAT } \\
\hline \multicolumn{1}{c|}{ OPPORTUNITY } & $\begin{array}{l}\text { Banyak siswa yang belum memutuskan } \\
\text { perguruan tinggi tujuan. }\end{array}$ & 1 & $\begin{array}{l}\text { Meningkatnya jumlah perguruan tinggi } \\
\text { di Maluku Utara }\end{array}$ \\
\hline 2 & $\begin{array}{l}\text { Ketersediaan beasiswa dari berbagai } \\
\text { sumber khususnya CSR }\end{array}$ & 2 & $\begin{array}{l}\text { Kebijakan diizinkannya perguruan } \\
\text { tinggi lain menyelenggarakan program } \\
\text { pendidikan jarak jauh }\end{array}$ \\
\hline
\end{tabular}




\section{KESIMPULAN DAN SARAN}

Sesuai hasil penelitian dan pembahasan, dapat ditarik kesimpulan bahwa:

1. Berdasarkan bauran pemasaran, siswa SLTA di Maluku Utara lebih mempertimbangkan masuk ke Perguruan Tinggi yang mempunyai program studi/jurusan yang sesuai minatnya, SPP-nya terjangkau, lokasinya dekat pusat kota, memiliki dosen yang kapabel, proses pendaftarannya mudah diakses, dan meiliki sarana prasarana ruang belajar yang nyaman.

2. UPBJJ-UT Ternate mempunya peluang dalam melakukan sosprom ke siswa SLTA karena sebagian besar dari mereka belum memutuskan memilih masuk ke perguruan manapun. Apalagi di UT banyak tersedia beasiswa seperti Bidimisi dan CSR UT tentu akan menarik minat mereka untuk kuliah di UT.

3. Dari aspek tantangan, saat ini sudah banyak Perguruan Tinggi di Maluku Utara, sehingga UPBJJ-UT Ternate harus mampu memberikan sosialisasi tentang keunggulan UT dari perguruan tinggi lainnya yang ada di Maluku Utara, seperti: proses pendaftarannya terbuka untuk umum dan segala Usia, biayanya terjangkau dan dapat kuliah di mana saja sehingga mudah diakses.

Dari kesimpulan di atas, disarankan agar siswa tertarik melanjutkan pendidikan di Universitas Terbuka, maka Universitas Terbuka penting untuk meyediakan program studi yang menjadi minat siswa. Dengan sistem belajar jarak jauh, maka tentunya dapat mendekatkan layanan pendidikan bagi siswa yang ingin kuliah, namun tidak harus meninggalkan tempat.

\section{REFERENSI}

Arikunto, Suharsimi 2002. Prosedur Penelitian. Jakarta: Bhineka Cipta.

Arsyad, Lincolin 2012. Ekonomi Pembangunan. Tanggerang: Percetakan Universitas Terbuka

Dharmmesta, Basu S. 2012. Manajemen Pemasaran. Tanggerang : Percetakan Universitas Terbuka

Erwin dan Permata, S. Utami. 2020. Analisis Pengaruh Bauran Promosi Terhadap Keputusan Konsumen Pada PT. Bank Negara Indonesia (Persero) Tbk Cabang Majene. Jurnal of Economic, Public, and Accounting (JEPA), Vol.3, No.1, Hal. 41-47

Gilbert, David. 2003. Retail marketing management (2nd ed.). England: Prentice -Hall

Hurriyati, Ratih. 2005. Bauran Pemasaran dan Loyalitas Konsumen. Bandung: Alfabeta

Kopertis XII. 2013. Daftar dan Profil Perguruan Tinggi di Kopertis Wilayah XII. http://www.kopertis12.or.id. diunggah tanggal 21 Agustus 2018 
Kotler, Philip dan Amstrong, Gery. 2008. Prinsip-prinsip Pemasaran. Jilid I Edisi XII. Diterjemahkan oleh Bob Sabran. Jakarta: Erlangga.

Lupiyoadi, Rambat dan A. Hamdani. 2008. Manajemen Pemasaran Jasa. Jakarta: Salemba Empat

Miles, Mattew B dan A. Michael Huberman. 2007. Analisis Data Kualitatif, Buku sumber tentang metode- metode baru. Jakarta: Universitas Indonesia. Press

Moleong, L.J. 2011. Metodologi Penelitian Kualitatif Edisi Revisi. Bandung

Nasution. 2003. Metode Research, Jakarta : PT. Bumi Aksara. Nitisemito

Notoatmodjo, S. 2005. Metodologi Penelitian Kesehatan. Jakarta : Rineka Cipta.

Sugiyono. 2007. Metode Penelitian Bisnis, Bandung : CV. Alfabeta

Sulaiman. 2013. Menciptakan Nilai Pelanggan, Kepuasan Dan Loyalitas. http://www.academia.edu/5004226/menciptakan nilai pelanggan kepuasan dan loyalitas makalah individu. diunggah tanggal 21 Februari 2017

Undang-Undang Nomor 20 Tahun 2003 Tentang Sistem Pendidikan Nasional, Jakarta: Depdiknas. Departemen Pendidikan Nasional, 2005.

Universitas Terbuka. 2018. Rencana Strategi Bisnis Universitas Terbuka Tahun 2016-2020 Edisi Revisi.

Zeithaml dan Bitner. 2000. Service Marketing: Integrating Customer Focus Across. the Firm, me Graw Hill. 